\title{
Effect of an educational programme on critical care nurses' competence at two tertiary hospitals in Malawi
}

\author{
Rodwell Gundo $^{1,3}$, Beatrice Gundo ${ }^{2}$, Ellen Chirwa ${ }^{3}$, Annette Dickinson ${ }^{1}$, Gael Janine Mearns ${ }^{1}$
}

1. Auckland University of Technology, School of Clinical Sciences, Auckland 1142. New Zealand

2. Kamuzu Central Hospital, Lilongwe. Malawi

3. Kamuzu University of Health Sciences, Blantyre, Malawi

*Corresponding Authors: Rodwell Gundo; E-mail: rgundo@kcn.unima.mw

Bbstract
Background
Critical care specialty deals with the complex needs of critically ill patients. Nurses who provide critical care are expected to possess
the appropriate knowledge and skills required for the care of critically ill patients. The aim of this study was to assess the effect of an
educational programme on the competence of critical care nurses at two tertiary hospitals in Lilongwe and Blantyre, Malawi.
Methods
A quantitative pre- and post-test design was applied. The training programme was delivered to nurses (n = 41) who worked in
intensive care and adult high dependency units at two tertiary hospitals. The effect of the training was assessed through participants'
self-assessment of competence on the Intensive and Critical Care Nursing Competence Scale and a list of 10 additional competencies
before and after the training.
Results
The participants' scores on the Intensive and Critical Care Nursing Competence Scale before the training, M $=608.2, \mathrm{SD}=59.6$
increased significantly after the training, $\mathrm{M}=684.7, \mathrm{SD}=29.7, \mathrm{p}<.0001$ (two-tailed). Similarly, there was a significant increase in the
participants' scores on the additional competencies after the training, $\mathrm{p}<.0001$ (two-tailed).
Conclusion
The programme could be used for upskilling nurses in critical care settings in Malawi and other developing countries with a similar
context.
Key words; Critical Care Nursing; Needs Assessment; Malawi; Developing Countries; Intensive Care Units

\section{Introduction}

Critical care is a specialty which serves diverse needs of patients with actual or potential life-threatening organ dysfunction ${ }^{1}$. Patients requiring critical care have complex needs and receive multiple therapies which require technical and/or artificial life support ${ }^{2}$. The complex environment and inability to operate the equipment triggers stress among nurses who provide advanced care ${ }^{3}$. Therefore, critical care nurses are expected to possess appropriate knowledge and skills to cope with the challenges of critical illness in an environment that is fast evolving in terms of science and technology $y^{4}$.

The demand for critical care services in developing countries is high due to the increased burden of illnesses which culminate in critical illness and require critical care ${ }^{5,6}$. Malawi, located in the sub-Saharan Africa, is one of the countries worst affected by the burden of both communicable and noncommunicable diseases (NCDs). As an illustration, $\mathrm{HIV} /$ Acquired Immune Deficiency Syndrome (AIDS) account for $34.9 \%$ of Total Disability Adjusted Life Years (DALYs) ${ }^{7}$. HIV infection and its associated opportunistic infections are the most common cause of hospitalisation and create a significant burden on the country's health system $^{8}$. HIV also increases the risk of NCDs which are the second leading cause of deaths among adults, accounting for $16 \%$ of all deaths ${ }^{7}$. These circumstances create enormous challenges for health professionals especially nurses who are at the frontline of critical care service delivery.

Ironically, there are limited resources for the care of critically ill patients despite the high burden of illness in the developing countries including Malawi ${ }^{9,10}$. Among other challenges, there is limited infrastructure for critical care, limited supply of drugs, medical equipment, electricity power failure, and lack of pre-hospital emergency medical systems ${ }^{6,11,12}$. In the absence of pre-hospital care, critically ill patients die or their conditions worsen before they reach the hospital. Furthermore, there is critical shortage of well-trained staff with critical care training which presents major challenges in the delivery of critical care ${ }^{13,14}$. These challenges demand that critical care staff, especially nurses, gain appropriate competence to optimise their role in such resource poor settings.

Unlike developed countries where post-registration critical care courses exist, such courses are not available in the developing countries such as Malawi and Rwanda. Therefore, the nurses in the developing countries rely on basic nursing 
education which does not adequately prepare them for practice in critical care settings ${ }^{14,15,16}$. Previous studies which were conducted in Malawi reported that lack of competence among critical care nurses in Malawi contributes to suboptimal care of critically ill patients and their families ${ }^{15,17}$. In addition, Gundo ${ }^{15}$ and Barnes ${ }^{16}$ observed that competency gaps are aggravated by annual rotation of nurses to different departments of the hospital, which leads to loss of expertise in specific critical care settings. This situation requires strategies that would address the competence gaps to ensure optimal provision of care to critically ill patients.

In the absence of critical care nurse training programmes, training and skill acquisition programs are some of the highly valued priorities to be considered for the improvement of critical care nursing in the developing countries. Different authors have reported an improvement in nurses' knowledge, a reduction of nursing errors in critical care settings and positive patient outcomes following staff training on different aspects of patient care ${ }^{16,18,19}$. The study by Mpasa ${ }^{19}$ was conducted in Malawi and reported an improvement in nurses' knowledge on the management of endotracheal tube cuff pressure after an educational intervention. However, it is not known whether an educational intervention using available resources could improve the nurses' overall competence in critical care. The aim of this study was to assess the effect of an educational programme on the competence of critical care nurses at two tertiary hospitals in Lilongwe and Blantyre, Malawi.

\section{Methods \\ Study design}

A quantitative pre- and post-test design was carried out to assess the effect of the training programme.

\section{Study setting}

The study was conducted at two tertiary hospitals in Malawi, referred to as A and B in the present study. The two hospitals were purposively selected because they are the biggest tertiary facilities which offer specialized services and have busy ICUs and HDUs. Hospital A is a 900 bedded referral and teaching hospital which is located in the capital city and serves a catchment area of 7.5 million people in the country's central region ${ }^{20,21}$. Hospital B is another referral and teaching hospital which is located in the country's southern region which has a population of 7.7 million $^{22}$. The hospital has a bed capacity of 1350 and receives referred patients from surrounding district hospitals, health centres, and private healthcare facilities ${ }^{23}$. At the time of data collection, there were three adult high dependency units (HDU) and a five bedded general intensive care unit (ICU) at Hospital A; six adult HDUs and four-bedded general ICU at Hospital B. In addition, there were 102 nurses working in the ICU and HDUs at the two hospitals.

\section{Participants}

Participants who received the training were nurses working in ICU and adult HDUs at the two tertiary hospitals in Malawi.

\section{Sample size for the training}

GPower software was used to calculate the sample size ${ }^{24}$. We selected a conservative effect size of $\mathrm{d}=0.5$ from which to calculate the sample size. For the study to be powered at $80 \%$, alpha $=0.05$, a sample size of 34 was required. To allow for a dropout rate of no more than $20 \%, 41$ participants were required to take part in the training.

\section{Training programme}

There were two sessions of the training, one at each hospital over three days. The facilitators comprised critical care nurses, clinicians and anaesthetists who either supervised the nurses in ICUs and HDUs or worked with the nurses in the units at each hospital. The involvement of local facilitators was considered important to ensure acceptability of the programme and continuity of learning of the nurses after the training. The demographic profile of the facilitators is presented in Table 1.

\section{Table 1: Demographic profile of the facilitators of the training}

\begin{tabular}{|c|c|c|c|}
\hline Session & Facilitator & Qualification & $\begin{array}{l}\text { Critical care } \\
\text { experience } \\
\text { (years) }\end{array}$ \\
\hline \multirow[t]{6}{*}{1} & 1 & $\begin{array}{l}\text { MSc - Intensive and } \\
\text { critical care nursing }\end{array}$ & 4 \\
\hline & 2 & $\begin{array}{l}\text { MSc - Intensive and } \\
\text { critical care nursing }\end{array}$ & 4 \\
\hline & 3 & $\begin{array}{l}\text { MSc - Intensive and } \\
\text { critical care nursing }\end{array}$ & 6 \\
\hline & 4 & $\begin{array}{l}\text { Diploma - Clinical } \\
\text { Medicine }\end{array}$ & 10 \\
\hline & 5 & Diploma - Anaesthesia & 13 \\
\hline & 6 & $\begin{array}{l}\text { Diploma - Anaesthesia } \\
\text { Short course - Pain } \\
\text { management }\end{array}$ & 15 \\
\hline \multirow[t]{5}{*}{2} & 1 & $\begin{array}{l}\text { MSc - Intensive and } \\
\text { critical care nursing }\end{array}$ & 4 \\
\hline & 2 & $\begin{array}{l}\text { MSc - Intensive and } \\
\text { critical care nursing }\end{array}$ & 6 \\
\hline & 3 & BSc-Nursing & 4 \\
\hline & 4 & Diploma - Anaesthesia & 10 \\
\hline & 5 & $\begin{array}{l}\text { Diploma - Anaesthesia } \\
\text { BSc - Health Service } \\
\text { Management }\end{array}$ & 16 \\
\hline
\end{tabular}

The topics for the training were selected by a team of local nursing experts $(n=4)$ and an anaesthetist $(n=1)$ based on learning needs of the nurses which were identified in the first phase of the study. As reported in a separate publication, the learning needs of the nurses were related to five dimensions of knowing namely; theoretical knowing, practical knowing, managerial knowing, ethical and professional knowing, and ability to interpret and $a c^{25}$. The topics selected for the training were those that were suggested by the majority of the participants and deemed relevant to the context in Malawi. The topics were: nursing care of a critically ill patient; selected drugs used in critical care; suctioning; patient assessment; pain management and sedation; interpretation of arterial blood gases; basic electrocardiogram (ECG) interpretation (3 Lead); meeting patients nutritional needs; care of family members of admitted patients; care of a patient with chest drains; head injury; shock; sepsis; fluid management; mechanical ventilation; documentation and cardiopulmonary resuscitation (CPR).

Development of the content was led by the primary author (RG), a trained critical care nurse in consultation with the nursing experts and facilitators of the training. A preparatory meeting with the facilitators was convened a week before the 
training at each hospital. During the meeting, the facilitators were invited to make suggestions on the content and approach for the training. The resources for the training included Liquid Crystal Display (LCD) projector, Resusci-Annie and Laerdal manikins for CPR, resuscitation bags, intravenous fluids, monitors, perfusers, syringes, bandages and portable Newport ventilator. Teaching strategies included lectures, group discussions, skill sessions and return demonstrations.

Table 2: Summary of participants' scores on ICCN-CS-1 preand post-training

\begin{tabular}{|c|c|c|c|}
\hline \multirow[b]{2}{*}{ ICCN-CS-1 Domain } & Time 1 & Time 2 & \multirow{2}{*}{$\begin{array}{l}\text { p-value } \\
\left(\begin{array}{c}T w \\
\text { tailed })\end{array}\right.\end{array}$} \\
\hline & $\begin{array}{l}\text { Pre-training } \\
\text { Mean (SD), } \\
\mathrm{N}=41\end{array}$ & $\begin{array}{l}\text { Post training } \\
\text { Mean (SD), } \\
\mathrm{N}=41\end{array}$ & \\
\hline 1. Knowledge & $145.5(15.7)$ & $170.9(8.7)$ & $<0.0001^{*}$ \\
\hline 2. Skill & $146.8(21)$ & $168.6(14.2)$ & $<0.0001^{*}$ \\
\hline $\begin{array}{l}\text { 3. Attitude and } \\
\text { value }\end{array}$ & $173.5(10.9)$ & $175.6(6.5)$ & 0.147 \\
\hline 4. Experience & $142.5(21.0)$ & $170.0(10.0)$ & $<0.0001^{*}$ \\
\hline $\begin{array}{l}\text { Total competence } \\
\text { score on ICCN-CS-1 }\end{array}$ & $608.2(59.6)$ & $684.7(29.7)$ & $<0.0001^{*}$ \\
\hline
\end{tabular}

${ }^{*}$ Significant values

Table 3: Summary of participants' scores on additional competencies pre-and post-training

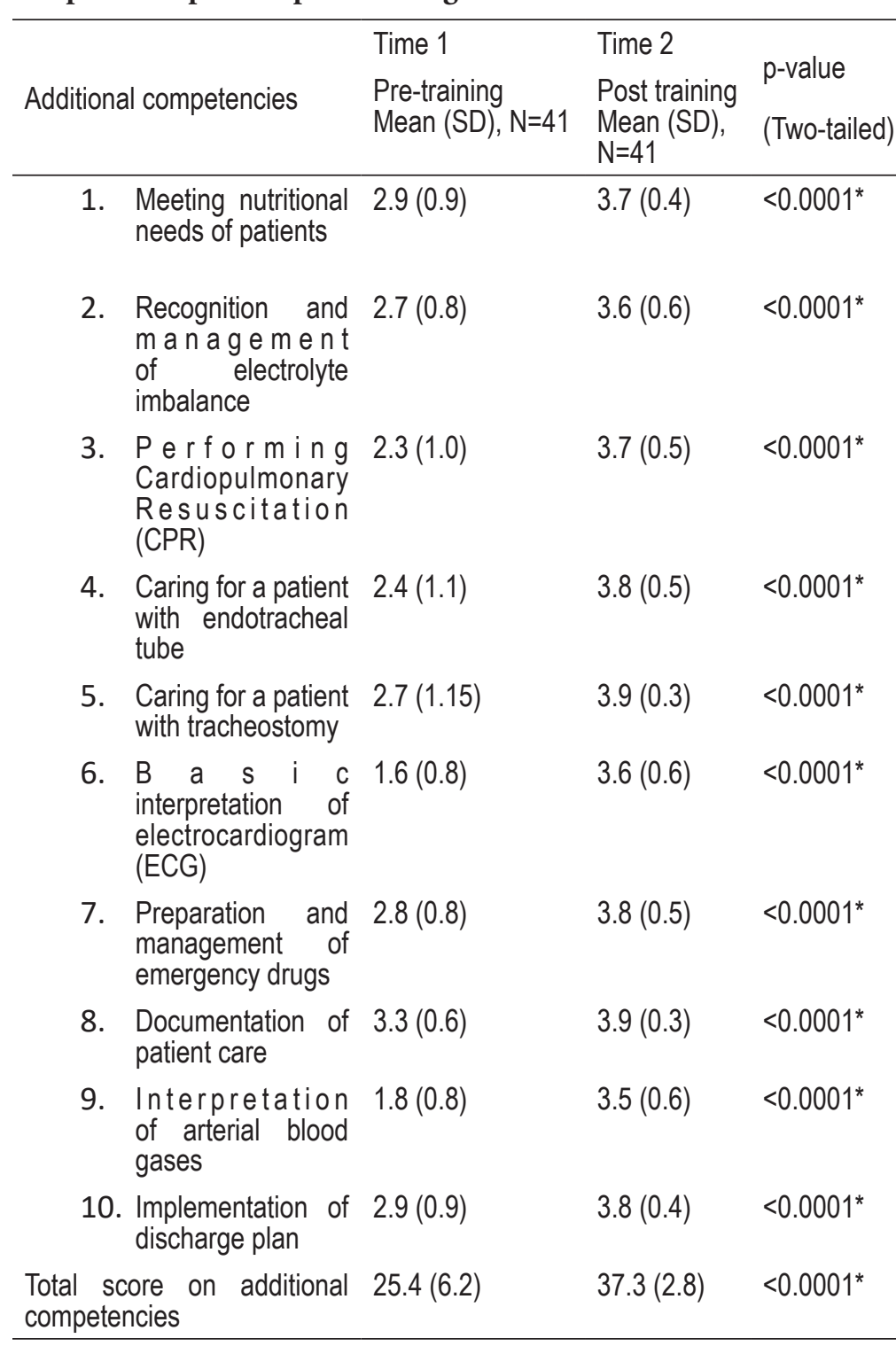

Involvement of the management team at each hospital was also considered important to ensure acceptability of the training programme. As per common practice during trainings in Malawi, the primary author (RG) requested the management team to delegate a senior member of staff to officially open and close the training. Each participant was provided with a writing pad, a pen and a copy of the programme with a list of topics and time schedule. At the beginning of each day, one participant was requested to take notes for the day's session to report back to the group the following day. The daily reports helped the participants recap what had been learned the previous day. The participants were divided into groups during practice sessions which were supervised and guided by the facilitators.

\section{Data collection}

Convenience sampling was used to identify the potential participants for the training from the ICUs and HDUs at the two hospitals. The participants who expressed interest provided their contact details. The primary researcher then negotiated with nurse leaders at each hospital to allow the participants to attend the training. Consultation with the nurse leaders was important to ensure that staffing levels and hospital services were not disrupted while the nurses attended the three-day training. The participants were requested to perform a paper-based self -assessment of their competence on the Intensive and Critical Care Nursing Competence Scale (ICCN-CS-1) and 10 additional competencies (Q3) before and after the training.

\section{Data collection instruments}

The ICCN-CS-1 is a self-assessment scale which was developed through a Delphi study in Finland ${ }^{26}$. The tool has 144 items related to knowledge, skill, attitude and value, and experience domains. Each of the items is assessed on a 5-point Likert scale as follows:

Knowledge and skill bases (1- very poorly, 2- poorly, 3 - neither poor nor good, 4- well, 5- very well)

Attitude and value base (1- fully disagree, 2- disagree, 3- neither disagree nor agree, 4- agree, 5 - fully agree) Experience base (1- fully insufficiently, 2insufficiently, 3- neither insufficiently nor sufficiently, 4- sufficiently, 5- fully sufficiently).

The total scores are classified as poor competence $(=1,144-288$, Likert scale $1-2 \times 144)$, moderate competence $(=2,289-432$, Likert scale $2-3 \times 144)$, good competence $(=3,433-576$, Likert scale $3-4 \mathrm{x}$ $144)$ and excellent competence $(=4,577-720$, Likert scale 4-5 x 144). Previous studies which used the tool reported Cronbach's alpha which ranged between 0.87 and 0.98 , indicating a reliable and internally consistent tool ${ }^{26,27}$. In this study, alterations to the tool were not permitted due to copyright restrictions by the authors ${ }^{26}$ therefore an additional competency scale was developed.

Local nursing experts in Malawi $(n=4)$ assessed content validity of the ICCN-CS-1 questionnaire and identified the additional competencies not included in the questionnaire but relevant to the context in Malawi (see Table 3). The additional competencies were assessed in a separate questionnaire (Q3) on a 4-point Likert scale as follows: 1- poor competence, 
2- moderate competence, 3- good competence and 4 excellent competence. Assessment of the effectiveness of the programme was based on comparison of competence scores on ICCN-CS-1 (Q1) and additional competencies (Q3) before and after the training. In addition, participants completed training evaluation form after the training.

\section{Data analysis}

The data were entered into SPSS application, version 25 by the primary author $(R G)$ for analysis. The data were normally distributed therefore descriptive statistics, mean with standard deviation and frequencies were used to summarize the participants' scores and responses. A paired-samples t-test was conducted to compare the scores before and after the training. The results are presented in Tables.

\section{Ethical considerations}

The study was approved by Auckland University of Technology Ethics Committee in New Zealand (reference number 15/439) and National Health Sciences Research Committee in Malawi, approval number NHSRC \#1533. Permission to use the ICCN-CS-1 was sought from the copyright author. The participants who expressed willingness to participate in the training provided written consent.

\section{Results}

A total of 41 nurses were recruited in the study. There were 18 nurses (44\%) in the first session at the hospital in Lilongwe and 23 nurses (56\%) in the second session in Blantyre. The participants comprised nurse-midwife technicians, 58.5\% $(n=24)$ and registered nurses, $41.5 \%(n=17)$. Majority of the nurses worked in HDU, $76 \%(n=31)$ while $24 \%(n=10)$ worked in ICUs. The mean age was 33 years $(\mathrm{SD}=9.5)$.

The total competence scores on ICCN-CS-1 before the training, Time 1 ranged from 483 to $697(M=608.2, S D=$ 59.6). The competence scores increased after the training, Time 2 , ranging from 617 to $720(M=684.7, S D=29.7)$. The increase was statistically significant, $p<.0001$ (twotailed). The mean increase in the competence score was 76.9, $95 \%$ CI [59.3, 94.5]. With regards to ICCN-CS-1 domains, the increase on attitude and value domain was not statistically significant, $p<.147$ (two-tailed). Details of the results are presented in Table 2.

Similarly, there was an increase in scores on all additional competencies after the training and the differences were statistically significant, $p<.0001$ (two-tailed). The overall score on the additional competencies from Time 1 , pretraining ( $M$ $=25.4, S D=6.2)$ to Time 2 , post training $(M=37.3, S D=$ 2.8 ), was also statistically significant, $t(40)=13.3, p<.0001$ (two-tailed). The mean increase in the overall score was 11.9, 95\% CI $[10.1,13.8]$. See Table 3 for details of this process.

The training programme was rated very relevant and relevant by $85 \%(n=35)$ and $15 \%(n=6)$ of the participants respectively at the end of the training. Majority, $98 \%(n=40)$ of the participants indicated that the objectives were clear and realistic, and that they would be able to apply what they had learnt to nursing practice.

\section{Discussion}

The study assessed the effect of a three-day training on the competence of critical care nurses in Malawi. The participants' scores on the ICCN-CS-1 and additional competencies (Q3) increased significantly at the end of the training. The content of the training was based on learning needs of nurses which were identified in the earlier phase of the larger study ${ }^{25}$. The participants considered the training relevant and expressed satisfaction with the content and approach.

The significantincrease in the participants' overall competence and scores on three domains of competence; knowledge, skill and experience after the training is consistent with the outcome of similar training programmes in critical care settings in Malawi and other developing countries ${ }^{16,19,28-30}$. For example, the study by Pubudu ${ }^{30}$ on nursing intensive care skills training in Sri Lanka, reported that post-test scores of participants were significantly higher than pre-test scores. Similarly, the study by Barnes and Paterson-Brown ${ }^{16}$ which was conducted in Malawi reported significant improvement in the nurses' confidence in the management of critical illness after a training intervention. However, there was minimal increase in the scores on attitude and value domain of ICCN-CS-1 in the present study. The items in this domain explored nurses' perception of and desire to master certain critical care skills. Therefore, the results could be attributed to the lack of post registration critical care nursing course in Malawi and none of the participants was trained in critical care nursing ${ }^{25}$.

Furthermore, there was significant increase in participants' scores on all the additional competencies, meeting nutritional needs of patients; recognition and management of electrolyte imbalance; performing cardiopulmonary resuscitation (CPR); caring for a patient with endotracheal tube; caring for a patient with tracheostomy; basic interpretation of ECG; preparation and management of emergency drugs; documentation of patient care; interpretation of arterial blood gases; and implementation of discharge plan. These competencies were also identified as critical by the participants in the previously cited study by Pubudu ${ }^{30}$. Nurses are responsible for monitoring of the critically ill patients and making decisions based on the information gathered from different monitors and through different investigations. They are also usually the first to respond to in-hospital emergencies such as cardiac arrests therefore they are expected to master the basic resuscitation skills ${ }^{31}$.

The results support findings of previous studies that assessed the effect of training interventions on similar competencies; management of endotracheal tube cuff pressure ${ }^{19}$, cardiac life support skills of nursing staff in critical areas of care ${ }^{18,31}$, the care of a patient who is intubated and undergoing mechanical ventilation ${ }^{32}$, knowledge and practices of electrocardiogram interpretation ${ }^{31,33}$. As an example, the study by Bojsen et al. ${ }^{33}$ on acquisition and retention of ECG interpretation skills reported that the overall mean test score improved significantly after a training.

The results underscore the need to introduce post registration training programmes and ongoing educational initiatives for the critical care nurses in Malawi. The training implemented in this study was based on learning needs of the nurses at the two hospitals. Educational initiatives that are tailored to respond to the needs of clinical service are valuable for the advancement of critical care nursing practice ${ }^{34}$. The findings echo the importance of understanding the context in developing training programmes as proposed by Harris, Fioratou, and Broadis ${ }^{35}$ in a previous study which evaluated barriers and facilitators faced by staff involved in burns education training programmes in Malawi. As observed by Bojsen, et al. ${ }^{33}$ newly acquired skills are rapidly lost when a training intervention is not repeated; ongoing implementation of the training is imperative to improve the 
nurses' competence.

It is worth mentioning that the study was conducted before the corona virus disease (COVID-19) pandemic which has increased the demand for competent critical care nurses worldwide $^{35}$. There is evidence that $20 \%$ of suspected and confirmed patients with SARS-CoV-2 infection develop severe hypoxemia and require critical care ${ }^{36}$. Therefore, the findings of the present study contributed a resource which can be used for orientation of new nurses, continuing education, and preceptorship programmes as a way of preparing the nurses for critical care nursing practice in Malawi and other countries with a similar context. We support calls for ongoing education of the critical care nurses to facilitate the transfer of knowledge into practice ${ }^{37}$. The involvement of local facilitators as was done in the present study could also help to minimise challenges, and ensure acceptability and sustainability of the educational programmes ${ }^{16,38}$. Further research is required to establish the nurses' learning needs that are specific to the management of critically ill COVID-19 patients.

\section{Limitations of the study}

The weaknesses of the study include the lack of equal representation of the participants from the two hospitals and the critical care units. The use of different facilitators for the two sessions of the training might have also affected the participants' experience of the training. However, the involvement of local staff at each hospital as facilitators was considered critical to ensure acceptability and sustainability of the training. In addition, the assessment of the effect of the training was based on subjective information. It is possible that participants overrated their level of competence. Future trainings should include objective assessment methods to assess the effect of the trainings.

\section{Conclusion}

The overall study addressed the need for an in-service training programme for critical care nurses which can be implemented using existing structures in Malawi and other developing countries with a similar context. In general, there was significant increase in competence scores of the participants after the training. Further research could be conducted to identify learning needs that are specific to the management of critically ill COVID-19 patients to be considered for inclusion in the programme. In spite of its limitations, the study contributed to the development of a specialist body of knowledge related to critical care nursing education and practice development within Malawi and other developing countries.

\section{Acknowledgement}

The whole study was conducted in partial fulfilment of the primary author's degree of Doctor of Philosophy at Auckland University of Technology (AUT) with funding from New Zealand Foreign Affairs and Trade Aid Program. Additional research funding was provided by AUT and National Commission for Science and Technology in Malawi. Preliminary findings were presented at the 2018 Australian and New Zealand Intensive Care Society Regional Annual Scientific Meeting.

\section{Author's contribution}

RG conceptualized and carried out the overall study, drafted and revised the manuscript. EC, AD and GM supervised the study and provided guidance at every stage. BG, EC, AD and
GM provided critical feedback on the manuscript.

\section{References}

1. Marshall, J. C., Bosco, L., Adhikari, N. K., Connolly, B., Diaz, J. V., Dorman, T., ... Zimmerman, J. (2017). What is an intensive care unit? A report of the task force of the World Federation of the Societies of Intensive and Critical Care Medicine. J Crit Care, 37, 270-276. https:// doi.org/http://dx.doi.org/10.1016/j.jcrc.2016.07.015

2. World Federation of Critical Care Nurses. (2019). Position statement on provision of a critical care nursing workforce. Retrieved from http://wfccn.org/wp-content/uploads/2019/09/WFCCN-WorkforcePS_17.9.19.pdf

3. Bagherian, B., Sabzevari, S., Mirzaei, T., \& Ravary, A. (2017). Meaning of caring from critical care nurses' perspective: A phenomenological study. J Intensive Crit Care, 3(3:33), 1-9. https://doi. org/10.21767/2471-8505.100092

4. Labeau, S., Chiche, J., \& Blot, S. (2012). Post-registration ICU nurses education: Plea for a European curriculum. Int J of Nurs Stud, 49, 127-128. https://doi.org/10.1016/j.ijnurstu.2011.07.014

5. World Health Organization. (2016). World Health Statistics 2016: Monitoring health for sustainable development goals. Geneva, Switzerland. Retrieved from http://www.who.int/gho/publications/ world_health_statistics/2016/en/

6. Murthy, S., Leligdowicz, A., \& Adhikari, N. K. J. (2015). Intensive care unit capacity in low-income countries: A systematic review. PLoS One, 10(1:e0116949). https://doi.org/10.1371/journal.pone.0116949

7. Government of the Republic of Malawi. (2017a). Health sector strategic plan II (2017-2022): Towards universal health coverage Lilongwe, Malawi: Ministry of Health.

8. Maheswaran, H., Petrou, S., Cohen, D., MacPherson, P., Kumwenda, F., Lalloo, D. G., . . . Clarke, A. (2018). Economic costs and healthrelated quality of life outcomes of hospitalised patients with high HIV prevalence: A prospective hospital cohort study in Malawi. PLoS One, 13(3), e0192991. https://doi.org/https://doi.org/10.1371/journal. pone. 0192991

9. Williams, G., Aliga, C. A., Daniel, N., Kabara, H., Adipa, F., \& Mbogo, M. (2018). Critical care in Africa: A new chapter. The World of Critical Care Nursing, 12(1), 12-15.

10. Gundo, R., Mearns, G., Dickinson, A., Smythe, L., \& Chirwa, E. (2019b). Development, implementation and evaluation of an in-service training programme for critical care nurses in Malawi. Auckland University of Technology, Auckland, New Zealand. Retrieved from http://hdl.handle.net/10292/12657

11. Carter, C. (2016). The nurse's role in delivering the global safe surgery campaign. Br J Nurs, 25(16), 907.

12. Limbu, S., Kongsuwan, W., \& Yodchai, K. (2019). Lived experiences of intensive care nurses in caring for critically ill patients. Nurs Crit Care, 24(1), 9-14. https://doi.org/10.1111/nicc.12349

13. Stafford, R. E., Morrison, C. A., Godfrey, G., \& Mahalu, W. (2014). Challenges to the provision of emergency services and critical care in resource-constrained settings. Glob Heart, 9(3), 319-323. https://doi. org/10.1016/j.gheart.2014.08.005

14. Munyiginya, P., Brysiewicz, P., \& Mill, J. (2016). Critical care nursing practice and education in Rwanda. South African Journal of Critical Care, 32(2), 55-57. https://doi.org/10.7196/SAJCC.2016. v32i2.272

15. Gundo, R., Mearns, G. S., Dickinson, A., \& Chirwa, E. (2019a). Contextual issues that influence preparedness of nurses for critical care nursing practice in Malawi. Malawi Med J, 31(2), 138-143. https://doi. org/https://dx.doi.org/10.4314/mmj.v31i2.6

16. Barnes, J., \& Paterson-Brown, L. (2017). Improving care of critically unwell patients through development of a simulation programme in Malawian Hospital. J Educ Train Stud, 5(6), 90-96. https://doi. 


\section{org $/ 10.11114 /$ jets.v5i6.2366}

17. Mula, C., Ncama, B. P., \& Maluwa, A. (2014). Nurses' competency and challenges in enteral feeding in the Intensive Care Unit (ICU) and High Dependency Unit (HDU) of a referral hospital, Malawi. Malawi Med J, 26(3), 55-59.

18. Mpambara, J., Musengimana, J. C., Ruhumuliza, V., \& Carlson, K. (2015). Training of advanced cardiac life support skills to nursing staff in critical areas of care. Rwanda Journal Series F: Medicine and Health Sciences, 2(2), 84. https://doi.org/http://dx.doi.org/10.4314/rj.v2i2.22F

19. Mpasa, F., Van Rooyen, D. R. M., Venter, D., P., J., \& Ten HamBaloyi, W. (2020). Improving nurses' knowledge of managing endotracheal tube cuff pressure in intensive care units: A quasiexperimental study. Health SA, 25(0), a1479. https://doi.org/10.4102/ hsag.v25i0.1479

20. Robinson, B., Purcell, L. P., Kajombo, C., Gallaher, J., \& Charles, A. (2021). Outcomes of stab wounds presenting to Kamuzu Central Hospital in Malawi. Malawi Med J, 33(1), 1-6. https://doi.org/https:// dx.doi.org/10.4314/mmj.v33i1.1

21. Prin, M., Kadyaudzu, C., Aagaard, K., \& Charles, A. (2019). Obstetric admissions and outcomes in an intensive care unit in Malawi. Int J of Obstet Anesth, 39, 99-104. https://doi.org/https://doi. org/10.1016/j.ijoa.2019.03.004

22. National Statistical Office (NSO) [Malawi]. (2019). 2018 Malawi population and housing census. Zomba, Malawi: NSO.

23. Gadama, Y., Kamtchum-Tatuene, J., Benjamin, L., Phiri, T., \& Mwandumba, H. (2019). The significant gap between international standards and stroke management practices at Queen Elizabeth Central Hospital (Malawi): An audit report. Malawi Med J, 31(4), 249-255. https://doi.org/https://dx.doi.org/10.4314/mmj.v31i4.6

24. Mayr, S., Buchner, A., Erdfelder, E., \& Faul, F. (2007). A short tutorial of GPower. Tutorials in Quantitative Methods for Psychology, $3(2), 51-59$.

25. Gundo, R., Mearns, G., Dickinson, A., Chirwa, E., \& Gundo, B. (2021). Patterns of knowing required for critical care nursing practice in Malawi. Int J Afr Nurs Sci, 14(100275). https://doi.org/https://doi. org/10.1016/j.ijans.2020.100275

26. Lakanmaa, R., Suominen, T., Perttilä, J., Ritmala-Castrén, M., Vahlberg, T., \& Leino-Kilpi, H. (2013a). Basic competence in intensive and critical care nursing: Development and psychometric testing of a competence scale. J Clin Nurs, 23(5-6), 799-810. https://doi. org/10.1111/jocn.12057

27. Shouryabi, A. A., Ghahrisarabi, A., Anboohi, S. Z., Nasiri, M., \& Rassouli, M. (2017). Psychometric properties of the Persian version of the Intensive and Critical Care Nursing Competence Scale version-1 (ICCN-CS-1). Electron Physician, 9(11), 5785-5792. https://doi.org/ http://dx.doi.org/10.19082/5785
28. Kim, H., \& Chang, S. J. (2021). Implementing an educational program to improve critical care nurses' enteral nutritional support. Aust Crit Care, 32, 218-222. https://doi.org/https://doi.org/10.1016/j. aucc.2018.04.001

29. Almarhabi, M., Cornish, J., \& Lee, G. (2021). The effectiveness of educational interventions on trauma intensive care unit nurses' competence: A systematic review and meta-analysis. Intensive Crit Care Nurs, 64(102931). https://doi.org/https://doi.org/10.1016/j. iccn.2020.102931

30. Pubudu, A. D. S., Stephens, T., Weilch, J., Sigera, C., De Alwis, S., \& Anthapattu, P. (2015). Nursing intensive care skills training: A nurse led, short, strucured and practical training program developed and tested in a resource-limited setting. J Crit Care, 30(2), 438.e437-438. e411

31. Tahboub, O. Y. H., \& Y1lmaz, U. D. (2019). Nurses' knowledge and practices of electrocardiogram interpretation. International Cardiovascular Research Journal, 13(3), 80-84. https://doi.org/ icrj.91025

32. Bloos, F., Mu"ller, S., Harz, A., Gugel, M., Geil, D., Egerland, K., Marx, G. (2009). Effects of staff training on the care of mechanically ventilated patients: A prospective cohort study. Br J Anaesth, 103(2), 232-237 https://doi.org/10.1093/bja/aep114

33. Bojsen, S. R., Räder, S. B. E. W., Holst, A. G., Kayser, L., Ringsted, C., Svendsen, J. H., \& Konge, L. (2015). The acquisition and retention of ECG interpretation skills after a standardized web-based ECG tutorial-a randomised study. BMC Med Educ, 15(36). https://doi. org/10.1186/s12909-015-0319-0

34. Williams, G., Fulbrook, P., Kleinpell, R., \& Alberto, L. (2020). The fifth international survey of critical care nursing organizations: Implications for policy. J Nurs Scholarsh, 52(6), 652-660. https://doi. org/10.1111/jnu.12599

35. Hetland, B., Lindroth, H., Guttormson, J., \& Chlan, L. L. (2020). 2020 - The Year that needed the nurse: Considerations for critical care nursing research and practice emerging in the midst of COVID-19. Heart Lung, 49, 342-343. https://doi.org/10.1016/j.hrtlng.2020.04.021

36. Buheji, M., \& Buhaid, N. (2020). Nursing human factor during COVID-19 pandemic. International Journal of Nursing Science, 10(1), 12-24. https://doi.org/10.5923/j.nursing.20201001.02

37. Almarhabi, M., Cornish, J., \& Lee, G. (2021). The effectiveness of educational interventions on trauma intensive care unit nurses' competence: A systematic review and meta-analysis. Intensive Crit Care Nurs, 64(102931). https://doi.org/10.1016/j.iccn.2020.102931

38. Harris, L., Fioratou, E., \& Broadis, E. (2016). Paediatric burns in LMICs: An evaluation of the barriers and facilitators faced by staff involved in burns education training programmes in Blantyre, Malawi. Burns, 42(5), 1074-1081. https://doi.org/10.1016/j.burns.2015.04.011 